\title{
Comparison in the incidence of anorectal malformations between a first- and third-world referral center
}

\author{
Andre P. Theron ${ }^{1^{\star}} \cdot$ Giulia Brisighelli $^{2} \cdot$ Anne E. Theron $^{3} \cdot$ Ernesto Leva $^{2} \cdot$ Alp Numanoglu $^{1}$
}

\begin{abstract}
Purpose Aim of study was to evaluate the differences in incidence and presentation of anorectal malformations (ARMs) between selected Pediatric Surgery Divisions in the Republic of South Africa (ZAR) and Italy.

Methods A retrospective cohort study involved analysis of clinical records of patients with ARM born between 2005 and 2012. Type of ARM, maternal age, birth weight, gestational age, presence of associated anomalies and delayed diagnosis were analyzed.

Results 335 patients were included in this study. Of note, statistically significant differences between the African and European patient groups were observed in a male predominance in the ZAR patient population. In addition, female recto-perineal fistulas were diagnosed in significantly more Italian patients than in ZAR. Furthermore, a more advanced maternal age and a lower gestational age was noted in the European cohort with a minimal delay in initial diagnosis as opposed to the African counterpart. Both centers reported recto-perineal fistula as the most common malformation in male patients.
\end{abstract}

Conclusion With the exception of perineal fistulas in females, the incidence of specific subtypes of ARMs was

${ }^{*}$ Andre P. Theron

andre.theron@gmail.com

1 Department of Pediatric Surgery, Red Cross War Memorial Children's Hospital, University of Cape Town, 6th Floor ICH Building, Klipfontein Road, Rondebosch, 7700 Cape Town, Republic of South Africa

2 Department of Pediatric Surgery, Fondazione IRCCS Ca' Granda Ospedale Maggiore Policlinico, Milan, Italy

3 Department of Physiology, University of Pretoria, Pretoria, Republic of South Africa similar in the two groups. This may be of importance when extrapolating European study conclusion to the South African setting.

Keywords Anorectal malformation - Incidence $\cdot$ South Africa · Italy

\section{Introduction}

Although classified as rare, anorectal malformations (ARM) constitute a significant proportion of congenital gastrointestinal defects. This spectrum of conditions constitutes significant socioeconomic and medical challenges as the involvement of multidisciplinary teams, including highly specialized surgical and nursing as well as prolonged rehabilitation and home care, is required for each patient $[1,2]$. These considerations are important in the various fiscal and management decision processes, from departmental and hospital levels, all the way through to the provincial and governmental policy makers.

The worldwide incidence of ARM is quote as 2-6 per 10,000 live births [3], although variability exists between countries, registers and years reported [4-6]. The International Clearing House Annual Report (2012) reported a birth prevalence of between 1.9 and 5.25 per 10,000 for 2010 in Italy depending on the region [3]. Data on the incidence of ARM in South Africa as established in 2010 are in keeping with these statistics, reporting 3.13 per 10,000 live births in the Western Cape Province (unpublished data) and 2.5 per 10,000 live births in the more northern University of Witwatersrand referral area [7]. There are differences in the clinical presentation of these malformations, and they may present as either isolated deformities, with associated anomalies or as part of a 
syndrome [8]. These factors affect the surgical intervention needed, rehabilitation strategies, prognosis and quality of life of the patients.

ARMs may be classified according to the internationally recognized Krickenbeck classification [9]. This allows for uniform reporting and comparisons, in males and females, based on the number of orifices visible in the perineum (females) and on fistula location (males) [9]. Associate malformations are present in $45-65 \%$ of neonates with ARMs, and include urogenital, cardiac, vertebral, spinal and gastrointestinal abnormalities most commonly [10, 11].

The low incidence of ARMs paired with the practical constraints of the South African health system provides challenges in the establishment of patient management and resource protocols. We rely heavily on first-world evidence-based medical protocols and trends. But important to note is that these parameters cannot always be generically extrapolated to the South African/African patients [12-14]. In an era of more personalized medicine, it becomes more evident that cultural, racial, ancestral genetic and environmental facts play significant roles [12-14].

In this pilot study, a retrospective observational analysis was done to establish whether baseline demographics in ARM patients were comparable between a prominent referral center in Italy (Fondazione IRCCS Ca Granda Ospedale Maggiore Policlinico di Milano, Milan), and its counterparts in South Africa (Red Cross War Memorial Children's Hospital and Tygerberg Children's Hospital, Cape Town). Established similarities in the relevant patient population would create the baseline from which research on patient management criteria may be extrapolated with more confidence in the sub-Saharan setting, or at very least, guide clinical trials and further studies which may be applicable.

\section{Methods}

This research project was approved by the Human Research Committee (Medical) at the University of Cape Town and the University of Stellenbosch (clearance certificate: HREC REF: 500/2013 and X14/01/001).

Retrospective data were obtained by analyzing patients' records over an 8-year period from 01 January 2005 till December 2012 that had been diagnosed with ARM. The South African group consists out of two tertiary academic hospitals namely Red Cross War Memorial Children's Hospital, University of Cape Town and Tygerberg Children's Hospital, University of Stellenbosch. For the Italian group, patient records from the Fondazione IRCCS Ca Granda Ospedale Maggiore Policlinico di Milano/Universita' degli studi di Milano were used. The two South African hospitals still keep folder records and rely on admission and theater registers to obtain the patient details.
The Italian hospital keeps a computerized central database that is updated as the patients are admitted, treated, operated on and reviewed for outpatient follow-up.

Main points of data collected were the date of birth, birth weight, gender, gestational age, maternal age, type of ARM, any other congenital abnormalities and if there was a delay in making the diagnosis of ARM. The definition of a delayed diagnosis was determined as that when the neonate was examined by medical personnel, the diagnosis was not made of ARM and the neonate was allowed to feed. For those babies that were born outside a medical facility, a delayed diagnosis was made if the neonate presented more than $48 \mathrm{~h}$ later.

The $t$ test and Fisher exact tests were used for statistical analysis.

\section{Results}

Results are summarized in Tables 1, 2, 3, and 4.

A total of 335 patients were included in the study over the 8 -year period. 214 patients $(64 \%)$ were diagnosed in the ZAR group and $121(36 \%)$ in the Italian group. Overall 186 $(56 \%)$ patients were male with $129(60 \%)$ in the ZAR group and 57 patients $(46 \%)$ in the Italian group $(p=0.02)$.

Of note is the statistical difference between the two groups in the gestational age $(p=0.02)$, maternal age $(p=0001)$, male to female ratio $(p=0.02)$. Average gestational age was 38.4 weeks in the ZAR and 37 weeks in the Italian group $(p=0.02)$, whereas maternal age was, respectively, 28 and 34 years $(p=0.0001)$, and birth weight 2722 and $2632 \mathrm{~g}(p=0.4)$. The initial missed diagnosis of ARM in the ZAR is statistically higher than is the Italian center. 57 of the 214 patients $(27 \%)$ had a delayed diagnosis in the ZAR group with only one in the Italian group $(p=0.0001)$. The female Italian patient was diagnosed at nine months with a recto-perineal fistula (Table 1).

Among the 186 males treated in both groups, the rectoperineal fistula was the most common malformation with $54(29 \%)$ patients affected 32 out of the $129(25 \%)$ males in the ZAR and 22 out of 57 (39\%) males in the Italian group $(p=0.08) .41(22 \%)$ had a recto-bulbar fistula, 31 (17\%) prostatic, $9(5 \%)$ recto-bladder neck fistula and 17 (9\%) imperforate anus without fistula with similar distributions in the two groups (Table 2).

Among a total of 145 females treated, the rectovestibular and the recto-perineal fistulas were the most common ARMs. These two clinical groups counted for 63 (44\%) and $43(30 \%)$, respectively. There was a statistically significant difference between the ZAR and the Italian group regarding the perineal fistulas with 13 out of 81 females (16\%) and 30 of 64 females (48\%), respectively, 
Table 1 Comparative data between ZAR and Italy

\begin{tabular}{llll}
\hline & ZAR & Italy & $p$ value \\
\hline Basic characteristics & & & \\
Gestational age (weeks) [SD] & $38.4[2.7]$ & $37[2.7]$ & 0.02 \\
Maternal age at childbirth (years), mean [SD] & $29[7.8]$ & $34[5.6]$ & 0.0001 \\
Male:female ratio & $1.6: 1$ & $1: 1.1$ & 0.02 \\
Mean birth weight (g) & 2722 & 2632 & 0.4 \\
Min/max birth weight (g) & $900 / 4530$ & $600 / 3840$ & \\
Delayed diagnosis (\%) & 27 & $<1$ & 0.0001 \\
Associated anomalies (\%) & 63 & 61 & 0.8 \\
\hline
\end{tabular}

Table 2 Comparative data for males with ARM

\begin{tabular}{|c|c|c|c|c|c|c|c|}
\hline \multirow[t]{2}{*}{ Type of ARM } & \multicolumn{2}{|l|}{ ZAR } & \multicolumn{2}{|l|}{ Italy } & \multicolumn{2}{|l|}{ Total } & \multirow[t]{2}{*}{$p$ value } \\
\hline & Number & Percentage $(\%)$ & Number & Percentage $(\%)$ & Number & Percentage $(\%)$ & \\
\hline \multicolumn{8}{|l|}{ Males $(n=186)$} \\
\hline Recto-perineal & 32 & 24.81 & 22 & 38.60 & 54 & 29.03 & 0.08 \\
\hline Recto-bulbar & 31 & 24.03 & 10 & 17.54 & 41 & 22.04 & 0.4 \\
\hline Recto-prostatic & 20 & 15.50 & 11 & 19.30 & 31 & 16.67 & 0.5 \\
\hline Recto-bladder neck & 4 & 3.10 & 5 & 8.77 & 9 & 4.84 & 0.1 \\
\hline Imperforate anus & 13 & 10.08 & 4 & 7.02 & 17 & 9.14 & 0.6 \\
\hline
\end{tabular}

Table 3 Comparative data for females with ARM

\begin{tabular}{|c|c|c|c|c|c|c|c|}
\hline \multirow[t]{2}{*}{ Type of ARM } & \multicolumn{2}{|l|}{ ZAR } & \multicolumn{2}{|l|}{ Italy } & \multicolumn{2}{|l|}{ Total } & \multirow[t]{2}{*}{$p$ value } \\
\hline & Number & $\begin{array}{l}\text { Percentage } \\
(\%)\end{array}$ & Number & $\begin{array}{l}\text { Percentage } \\
(\%)\end{array}$ & Number & $\begin{array}{l}\text { Percentage } \\
(\%)\end{array}$ & \\
\hline \multicolumn{8}{|l|}{ Females $(n=145)$} \\
\hline Recto-perineal & 13 & 15.85 & 30 & 47.62 & 43 & 29.66 & 0.0001 \\
\hline Recto-vestibular & 41 & 50.00 & 22 & 34.92 & 63 & 43.45 & 0.09 \\
\hline Cloaca & 9 & 10.98 & 8 & 12.69 & 17 & 11.64 & 0.8 \\
\hline Imperforate anus & 2 & 2.44 & 3 & 4.76 & 5 & 3.45 & 0.6 \\
\hline Recto-vaginal & 1 & 1.22 & 0 & 0.00 & 1 & 0.69 & \\
\hline Unknown & 15 & 17.07 & 1 & 1.59 & 16 & 10.34 & 0.001 \\
\hline
\end{tabular}

$(p=0.0001)$. Cloacae accounted for $17(11 \%)$ and imperforate anus without fistula for 5 (4\%) with no statistically difference between the two countries. Unfortunately, there was a high number of 'unknown' female ARM in the ZAR group which has the potential to skew the results (Table 3).

The associated anomalies for the ZAR and the Italian group were, respectively, $112(63 \%)$ and $74(61 \%)$ $(p=0.8)$ (Table 4).

\section{Discussion}

Moore et al. noted that ARMs contribute to a significant surgical burden throughout Africa [1, 15]. The authors even noted geographical differences of ARM presentations throughout the African continent [1]. Examples cited included the increased prevalence of cloacae and vestibular fistulae in their South African patient group, as opposed to recto-vaginal, recto-prostatic and anorectal malformation without fistula which wass more common in the Northern regions of the continent [1]. Although there has been an improvement in neonatal surgical outcomes in Africa over the last few decades and despite a recent review has showed that ARMs in African countries represent an important subject of publication, most of the evidence-based medical protocols still originate in firstworld countries [16]. Therefore, there is a need within the African context to find common points of departure, and to determine what findings can be extrapolated to our context, to improve intensive care facilities and staffing, coordination with rural and regional centers and to establish international collaborations with experts in the field, 
Table 4 Comparative percentage of associated congenital abnormalities

\begin{tabular}{lccl}
\hline & ZAR & Italy & $p$ value \\
\hline Percentage-associated & congenital abnormalities $(\%)$ & \\
Nil & 31.3 & 38 & 0.2 \\
Vertebral & 4.7 & 2.5 & 0.4 \\
Cardiac & 11.2 & 11.6 & 1 \\
Esophageal atresia & 0.9 & 1.7 & 0.6 \\
Renal & 11.7 & 10.7 & 0.9 \\
Limb abnormalities & 0.9 & 0.8 & 1 \\
Multiple & 21.5 & 33 & 0.01 \\
Unknown & 15.4 & 0 & 0.0001 \\
Other & 1.4 & 0.8 & 1 \\
\hline
\end{tabular}

Demographic studies are of importance as they may lead to better insights into the etiological origins of ARMs. Genetic associations are clearer in the syndromic ARMs, such as two nucleotide polymorphisms in the SALL1 gene in Townes-Brocks syndrome [17] and HLXB9 homeobox mutations in the autosomal dominant Currarino syndrome [18]. The exact genetics, perhaps in combination with environmental facts, remain ill defined [19]. Environmental studies have implicated paternal cigarette smoking and exhaust fume exposure as well as maternal obesity and diabetes as possible risk factors [20-22]. In addition, maternal exposure to industrial cleaning agents, multivitamin use and first trimester pyrexia have been implicated, although some of these findings could not be replicated in follow-up studies [21, 22]. ARM reported in a first- or second-degree relative was most noteworthy in increasing ARM risk [21, 22]. Analysis by a large European collaboration, the European consortium on anorectal malformations (ARM-NET), further identified various maternal risk factors implicated in the fetal development of complicated ARMs associated with additional congenital abnormalities and vertebral, anal, cardiac, tracheoesophageal, renal, and limb defects (VACTREL) [23]. These included maternal epilepsy, primiparity, low birth weight, multiple pregnancy, preeclampsia and fertility treatments [19, 23]. Further studies are needed in the sub-Saharan context to verify these, or other additional risk factors.

Patient parameters studied in this investigation yielded similar outcomes in the categories of birth weight and percentage-associated anomalies. The Italians patient sample displayed more of an equivalent male to female ratio, whereas the South African sample displayed more of a male predominance, which is similar to the literature published in both cases [2, 24]. The African statistic may be biased, as female ARM diagnoses may be more easily missed at birth without expert examination [25-27]. Of statistical significance additionally was a higher maternal age in the Italian sample (38 years old vs the South African 28 years old). This is in line with documented trends of delayed childbearing decisions in Europe and other firstworld countries [28].

Access to and completeness of patient records remains difficult in the overfull South African hospitals equipped with little or no electronic documentation systems [29, 30]. Moreover, as noted by Wijers et al., detailed definitive diagnosis according to the Krickenbeck criteria are often not denoted, and that together with possible misdiagnoses may account for some of the 'unknown' diagnoses in the South African arm of this study [9, 22, 28]. Of interest is that although the Italian establishment had treated fewer patients than the two South African centers, the relative percentage of the types of ARM diagnosed in males was not significantly different. When looking at the female presentation, there were statistically significant fewer diagnoses of recto-perineal ARMs in the South African group as compared to the Italian counterpart (15.85 vs $47.62 \%$, respectively). Moreover, the relative percentage of several associated congenital anomalies, including vertebral, cardiac, renal, limb and esophageal atresia, were relatively similar in both the South African and Italian groups. The statistical difference that was reported in the 'unknown' and 'multiple' classifications is, however, most likely due to incomplete medical records in the South African hospitals.

Of note in this study is the significant increase in delayed diagnoses when compared to the Italian counterpart (27 vs $<1 \%$ in the Italian group). A delayed diagnosis was determined as that when the neonate was examined by medical personnel, the diagnosis of ARM was not made and the neonate was allowed to feed. For babies that were born outside a medical facility, a delayed diagnosis was made if the neonate presented more than $48 \mathrm{~h}$ postpartum. A delay in diagnosis seems to be a common factor in the African setting, but not exclusive to it as can be seen in studies conducted in India, Ireland, Serbia and even Australia [26, 27, 31, 32]. The more benign forms of ARMs are the ones most commonly missed. The incidence in this report is similar to previously published figures, at $27 \%$ [26]. A study done in Malawi cited various possible reasons for delayed ARM diagnoses in that country, including a high proportion of home deliveries with a traditional birth attendant, distance needed to travel to definitive care settings and lack of health care workers [25]. Some presentations are more subtle at birth, thus diagnosis by insufficiently trained and skilled doctors or nurses may contribute to the diagnosis delay [25, 26, 31]. Delayed diagnoses lead to increased morbidity and mortality in these patients, as well as causing significant parental anxiety.

The sub-Saharan setting may have a cumulative influence on the management of these patients, as well as in the establishment of treatment policies. The relative dearth in 
resources and abject patient poverty as remnants from the former apartheid government are very real challenges that face the South African health system [29, 33]. Patients have poor access to referral centers, having to travel vast distances, leaving other dependents and possibly their jobs for relatively long periods during the course of treatment [33-35]. Many ARM diagnoses may be missed or delayed in the primary health care settings, rife with overcrowding, under facilitation and lack of specialist backup [29, 34]. Referral systems from rural clinics to tertiary facilities are poorly functional and difficult to access [29, 30, 33, 35]. Noted by Beudeker et al., Malawian patients that lived closer to tertiary institutions had a better diagnosis and survival rate [25]. Also to be taken into account, is the possibility of consultation with traditional healers which may miss or delay diagnoses [36, 37]. Clearer neonatal examination protocols may be recommended, as well as improved education of the more rural health care providers to increase their vigilance.

The results of this pilot study indicate that future policies resulting from European studies of ARMs may tentatively be extrapolated to the South African context. Of particular note is the formation of ARM-NET which aims to determine the incidence of ARM types, discuss treatment types and elucidate genetic and other epidemiological data applicable [24]. This powerful coordinated collaboration could lead the way in directing further research and African specific applications in the future.

\section{Conclusion}

Differences between first-world and third-world healthcare systems and research institutions remain evident. Patients with ARMs remain significant multidisciplinary and surgical management challenges, with their definitive etiology still vague. In this pilot study, incidence and type of ARM presentations were compared between an Italian referral hospital and a South African counterpart. Data obtained from both registries over an 8-year period revealed few differences in the demographics of the cases managed, with the exception of recto-perineal presentations in female patients. This may allow tentative extrapolation of future European data on ARMs as a starting point for defining, managing and coordinating hospital governance policies in the South African management of and research into the condition.

\section{References}

1. Moore SW, Alexander A, Sidler D, Alves J, Hadley GP, Numanoglu A, Banieghbal B, Chitnis M, Birabwa-Male D,
Mbuwayesango B, Hesse A, Lakhoo K (2008) The spectrum of anorectal malformations in Africa. Pediatr Surg Int 24(6):677-683. doi:10.1007/s00383-008-2131-y

2. Moore SW, Sidler D, Hadley GP (2008) Anorectal malformations in Africa. SAJS 43(4):174-175

3. International Clearing House for Birth Defects Surveillance and Research (2015) Annual Report 2011: with data for 2009. http:// www.icbdsr.org/filebank/documents/ar2005/Report2011.pdf.

Accessed 20 May 2015

4. International Clearinghouse Birth Defects Surveillance and Research (2007) Annual Report 2007: with data for 2005. The International Centre on Birth Defects-ICBDSR Centre, Via Carlo Mirabello 19, 00195 Roma, Italy

5. Cuschieri A, Group EW (2001) Descriptive epidemiology of isolated anal anomalies: a survey of 4.6 million births in Europe. Am J Med Genet 103(3):207-215

6. Lowry RB, Sibbald B, Bedard T (2007) Stability of prevalence rates of anorectal malformations in the Alberta Congenital Anomalies Surveillance System 1990-2004. J Pediatr Surg 42(8):1417-1421. doi:10.1016/j.jpedsurg.2007.03.045

7. Theron A, Loveland J (2014) Birth Prevalence of Anorectal Malformation in the Referral Area for the University of the Witwatersrand Tertiary Hospitals, South Africa. Epn J Pediatr Surg Off J Austrian Assoc Pediatr Surg Zeitschrift fur Kinderchirurgie

8. Marcelis C, de Blaauw I, Brunner H (2011) Chromosomal anomalies in the etiology of anorectal malformations: a review. Am J Med Genet A 155A(11):2692-2704. doi:10.1002/ajmg.a. 34253

9. Holschneider A, Hutson J, Pena A, Beket E, Chatterjee S, Coran A, Davies M, Georgeson K, Grosfeld J, Gupta D, Iwai N, Kluth D, Martucciello G, Moore S, Rintala R, Smith ED, Sripathi DV, Stephens D, Sen S, Ure B, Grasshoff S, Boemers T, Murphy F, Soylet Y, Dubbers M, Kunst M (2005) Preliminary report on the International Conference for the Development of Standards for the Treatment of Anorectal Malformations. J Pediatr Surg 40(10):1521-1526. doi:10.1016/j.jpedsurg.2005.08.002

10. Nah SA, Ong CC, Lakshmi NK, Yap TL, Jacobsen AS, Low Y (2012) Anomalies associated with anorectal malformations according to the Krickenbeck anatomic classification. J Pediatr Surg 47(12):2273-2278. doi:10.1016/j.jpedsurg.2012.09.017

11. Levitt MA, Pena A (2007) Anorectal malformations. Orphanet J Rare Dis 2:33. doi:10.1186/1750-1172-2-33

12. Abrams AL, Opiyo N, Cotton M, Crowley S, Okebe J, Wiysonge CS (2011) Supporting registration of child-focused clinical trials in Africa: the Child Strategy Project. SAMJ 101:804

13. Connor M, Bryerb A (2013) Stroke in South Africa. South African Medical Research Council. http://www.mrc.ac.za/ chronic/cdl1995-2005.htm. Accessed 25 May 2015

14. Taylor AL, Wright JT (2005) Importance of race/ethnicity in clinical trials: lessons From the African-American heart failure trial (A-HeFT), the African-American study of kidney disease and hypertension (AASK), and the antihypertensive and lipidlowering treatment to prevent heart attack trial (ALLHAT). Circulation 112(23):3654-3666. doi:10.1161/circulationaha.105. 540443

15. Moore SW, Sidler D, Hadley GP (2005) Anorectal malformations in Africa 43(4):174-175

16. Ekenze SO, Ajuzieogu OV, Nwomeh BC (2015) Neonatal surgery in Africa: a systematic review and meta-analysis of challenges of management and outcome. Lancet 385:S35. doi:10. 1016/S0140-6736(15)60830-3

17. Liang Y, Shen D, Cai W (2008) Two coding single nucleotide polymorphisms in the SALL1 gene in Townes-Brocks syndrome: a case report and review of the literature. J Pediatr Surg 43(2):391-393. doi:10.1016/j.jpedsurg.2007.09.079 
18. Hagan DM, Ross AJ, Strachan T, Lynch SA, Ruiz-Perez V, Wang YM, Scambler P, Custard E, Reardon W, Hassan S, Nixon P, Papapetrou C, Winter RM, Edwards Y, Morrison K, Barrow M, Cordier-Alex MP, Correia P, Galvin-Parton PA, Gaskill S, Gaskin KJ, Garcia-Minaur S, Gereige R, Hayward R, Homfray T (2000) Mutation analysis and embryonic expression of the HLXB9 Currarino syndrome gene. Am J Hum Genet 66(5):1504-1515

19. Wijers CHW, van Rooij IALM, Marcelis CLM, Brunner HG, de Blaauw I, Roeleveld N (2014) Genetic and nongenetic etiology of nonsyndromic anorectal malformations: a systematic review. Birth Defects Res C Embryo Today 102(4):382-400. doi:10. 1002/bdrc. 21068

20. Zwink N, Jenetzky E, Brenner H (2011) Parental risk factors and anorectal malformations: systematic review and meta-analysis. Orphanet J rare Dis 6:25. doi:10.1186/1750-1172-6-25

21. van Rooij IA, Wijers CH, Rieu PN, Hendriks HS, Brouwers MM, Knoers NV, de Blaauw I, Roeleveld N (2010) Maternal and paternal risk factors for anorectal malformations: a Dutch casecontrol study. Birth Defects Res A 88(3):152-158. doi:10.1002/ bdra.20649

22. Wijers CH, de Blaauw I, Marcelis CL, Wijnen RM, Brunner H, Midrio P, Gamba P, Clementi M, Jenetzky E, Zwink N, Reutter H, Bartels E, Grasshoff-Derr S, Holland-Cunz S, Hosie S, Marzheuser S, Schmiedeke E, Cretolle C, Sarnacki S, Levitt MA, Knoers NV, Roeleveld N, van Rooij IA (2010) Research perspectives in the etiology of congenital anorectal malformations using data of the International Consortium on Anorectal Malformations: evidence for risk factors across different populations. Pediatr Surg Int 26(11):1093-1099. doi:10.1007/s00383-0102688-0

23. Wijers CHW, Rooij I, Bakker MK, Marcelis CLM, Addor MC, Barisic I, Béres J, Bianca S, Bianchi F, Calzolari E, Greenlees R, Lelong N, Latos-Bielenska A, Dias CM, McDonnell R, Mullaney C, Nelen V, O'Mahony M, Queisser-Luft A, Rankin J, de ZymakZakutnia N, Blaauw I, de Roeleveld N, Walle HEK (2013) Anorectal malformations and pregnancy-related disorders: a registry-based case-control study in 17 European regions. BJOG 120(9):1066-1074. doi:10.1111/1471-0528.12235

24. de Blaauw I, Wijers CHW, Schmiedeke E, Holland-Cunz S, Gamba P, Marcelis CLM, Reutter H, Aminoff D, Schipper M, Schwarzer N, Grasshoff-Derr S, Midrio P, Jenetzky E, van Rooij IALM (2013) First results of a European multi-center registry of patients with anorectal malformations. J Pediatr Surg 48(12):2530-2535. doi:10.1016/j.jpedsurg.2013.07.022
25. Beudeker N, Broadis E, Borgstein E, Heij HA (2013) The hidden mortality of imperforate anus. Afr J Paediatr Surg 10(4):302-306. doi:10.4103/0189-6725.125417

26. Sinha SK, Kanojia RP, Wakhlu A, Rawat JD, Kureel SN, Tandon RK (2008) Delayed presentation of anorectal malformations. J Indian Assoc Pediatr Surg 13(2):64-68. doi:10.4103/0971-9261. 43023

27. Statovci S, Grajçevci S, Berisha M, Çeku G, Ademaj I, Ukeperaj $\mathrm{K}$ (2015) Late diagnosis of anorectal malformations in children. Surg Sci 6:143-148. doi:10.4236/ss.2015.63023

28. Benzies KM (2008) Advanced maternal age: are decisions about the timing of child-bearing a failure to understand the risks? CMAJ 178(2):183-184. doi:10.1503/cmaj.071577

29. Harris B, Goudge J, Ataguba JE, McIntyre D, Nxumalo N, Jikwana S, Chersich M (2011) Inequities in access to health care in South Africa. J Public Health Pol 32(S1):S102-S123

30. Nevhatalu $N$ (2014) Improving patient referral processes through electronic health record system: a case study of rural hospitals in Limpopo province. UNISA, South Africa

31. Wilson BE, Etheridge CE, Soundappan SVS, Holland AJA (2010) Delayed diagnosis of anorectal malformations: are current guidelines sufficient? J Paediatr Child Health 46(5):268-272. doi:10.1111/j.1440-1754.2009.01683.x

32. Tareen F, Coyle D, Aworanti OM, Gillick J (2013) Delayed diagnosis of anorectal malformation-a persistent problem. Ir Med J 106(8):238-240

33. Goudge J, Gilson L, Russell S, Gumede T, Mills A (2009) Affordability, availability and acceptability barriers to health care for the chronically ill: longitudinal case studies from South Africa. BMC Health Serv Res 9:75. doi:10.1186/1472-6963-9-75

34. Mojaki ME, Basu D, Letskokgohka ME, Govender M (2011) Referral steps in district health system are side-stepped. SAMJ 101:109

35. Richards DB, Jacquet GA (2012) Analysis of referral appropriateness in the Western Cape, South Africa, and implications for resource allocation. Afr J Emerg Med 2(2):53-58. doi:10.1016/j. afjem.2012.03.006

36. Hughes GD, Aboyade OM, Clark BL, Puoane TR (2013) The prevalence of traditional herbal medicine use among hypertensives living in South African communities. BMC Complement Altern Med 13:38. doi:10.1186/1472-6882-13-38

37. Sorsdahl K, Stein DJ, Grimsrud A, Seedat S, Flisher AJ, Williams DR, Myer L (2009) Traditional healers in the treatment of common mental disorders in South Africa. J Nerv Ment Dis 197(6):434-441. doi:10.1097/NMD.0b013e3181a61dbc 